\title{
ARTIGO CIENTÍEICO \\ Controle biológico de Spodoptera frugiperda Smith, 1797 (Lepidoptera: Noctuidae) por bactérias
}

\section{Biological control of Spodoptera frugiperda Smith, 1797 (Lepidoptera: Noctuidae) by bacteria}

\author{
Jessé Malveira Gomes ${ }^{1}$, Maurício Sekiguchi de Godoy ${ }^{2}$, Raphaela Vasconcelos Gomes Barreto ${ }^{3}$, Alcimar Galdino de Lira ${ }^{4}$ \\ Alricélia Gomes de Lima ${ }^{5}$
}

\begin{abstract}
Resumo: O milho é uma das culturas mais produzidas e importantes no mundo e apesar da elevada produção no Brasil, a sua produtividade ainda é comprometida pela ação de insetos pragas, sendo Spodoptera frugiperda Smith, 1797 praga chave. Em meio a esse desafio, o uso constante de inseticidas é utilizado buscando minimizar as perdas nas lavouras, porém, ocasionando grandes impactos ambientais. Uma das estratégias viáveis e promissoras na supressão desses artrópodes tem sido o Manejo Integrado de Pragas (MIP), que tem como alicerce o uso isolado ou consorciado de técnicas de controles, com o controle biológico uma das ferramentas mais sustentáveis do ponto de vista ecológico. Desta forma, o presente trabalho teve como objetivo avaliar a toxicidade da linhagem bacteriana 358.1 isolada do petróleo e do sobrenadante da cultura livre de células, no controle de lagartas de $3^{\circ}$ instar de $S$. frugiperda, comparando as taxas de mortalidade e efeitos sobre seu desenvolvimento à ação de inseticida químico comercial. O experimento foi realizado com lagartas de $3^{\circ}$ instar com três diferentes diluições de cultura da linhagem 358.1, do sobrenadante livre de células e do inseticida fenpropatrina. Solução salina foi utilizada como controle negativo. O experimento realizado com 358.1 não resultou em uma taxa significativa de mortalidade de $S$. frugiperda. Entretanto, o contato com a cultura de 358.1 e seu sobrenadante livre de células resultaram no aumento da duração da fase larval. Foram observados distúrbios morfofisiológicos, como o surgimento de adultos com asas atrofiadas, sendo desta maneira, promissora a realização de novos testes.
\end{abstract}

Palavras-chave: Milho, Lagarta do cartucho, Controle biológico.

\begin{abstract}
Corn is one of the most produced and important crops in the world and despite high production not Brazil, its production is still compromised by the action of insect pest, with Spodoptera frugiperda Smith, 1797 pest key. Because of this challenge, the continuous usage of insecticides is done aiming to minimize lost in the crops, however, causing great environmental impacts. One of the viable and promising strategies to this arthropod suppression has been the pest integrated management (PIM), which is based on the use of isolated or consortium of controlling techniques, the biological control being one of the most sustainable tools in an ecological perspective. Therefore, the present study had the goal of evaluating the toxicity of the 358.1 bacterial strain isolated from the oil and the supernatant of the cell free culture on the 3rd instar caterpillars control of $S$. frugiperda, comparing the death rates and effects on their development to the action of commercial chemical insecticide. The experiment was done with 3rd instar caterpillars with three different dilutions of the 358.1 strain, cell free supernatant and fenpropatrin insecticide. Saline solution as negative control. The experiments with the 358.1 strain didn't show a significant death rate for $S$. frugiperda. However, contact with the 358.1 culture and its cell free supernatant resulted in increased larval phase duration. Morphophysiological disorders were observed, such as the appearance of adults with atrophied wings, and it is therefore promising to perform new tests.
\end{abstract}

Key words: Corn, Cartridge crank, Biological control.

\footnotetext{
*Autor para correspondência

Recebido para publicação em 14/12/2017; aprovado em 20/03/2018

${ }^{1}$ Mestre em Horticultura Tropical, Universidade Federal de Campina Grande, Centro de Ciências Agroalimentar, Pombal; (88) 9204-8693, jesse_jmg@gmail.com.

${ }^{2}$ Doutor em Agronomia, Universidade Federal Rural do Semiárido, Mossoró; (84) 8753-6593, msdgodoy@ufersa.edu.br.

${ }^{3}$ Doutora em Biotecnologia, Universidade Federal Rural do Semiárido, Mossoró; (85) 8888-8202, rvgbarreto@ufersa.edu.br.

${ }^{4}$ Graduando em Agronomia, Universidade Federal Rural do Semiárido, Mossoró; (84) 9646-2274, alcimargaldino80@ hotmail.com.

${ }^{5}$ Graduanda em Agronomia, Universidade Federal Rural do Semiárido, Mossoró; (88) 9427-8492, alricelialima@hotmail.com.
} 


\section{INTRODUÇÃO}

Considerando a importância econômica da cultura do milho no mercado agrícola mundial, sua produção vem crescendo nos últimos anos. De acordo com a United States Department of Agriculture (USDA) (2014), os Estados Unidos da América (EUA) é o primeiro na produção desse grão, com o Brasil ocupando a terceira posição do ranking. Esta situação brasileira é devido ao emprego de tecnologias que proporcionaram o aumento de produção (140\%) e, nos últimos 20 anos, de ampliação das áreas cultivadas em 11,7\%, destacando-se as regiões Norte (72\%) e Nordeste (143\%) para o incremento em produtividade (CONAB, 2014).

Apesar desse panorama positivo, a produtividade da cultura do milho no Brasil, quando comparada com a de outros países, está muito abaixo (CONAB, 2014). Um dos fatores preponderante, está relacionado à alta incidência de pragas, com destaque para a lagarta do cartucho do milho ou lagarta militar Spodoptera frugiperda (J. E. Smith, 1797) (Lepidoptera: Noctuidae). Mesmo com o surgimento e a adoção de estratégias de controle relativamente recentes, o controle químico ainda predomina, acarretando gasto anual superior a meio bilhão de dólares para controlar esse inseto, e pouco eficiente, com perdas variando de 275 milhões a 1,5 bilhões de dólares anualmente (SOBER, 2010). De acordo com FAO, muitos países têm dificuldade para controlar a Spodoptera frugiperda. Na África os principais produtores relataram um prejuízo econômico que pode chegar a 6,5 bilhões de dólares a cada ano que a praga não consegue ser controlada com eficiência (EMBRAPA, 2018).

Desta forma, a utilização do Manejo Integrado de Pragas (MIP) com ênfase na tática do controle biológico, tem adquirido importância nas últimas décadas, pois, promovem uma maior sustentabilidade e viabilidade ecológica no agrossistema (WRIGHT, 2014). Considerando os danos e perdas econômicas que a lagarta-do-cartucho causa na cultura do milho, estudos sobre como combatê-la de maneira mais eficiente e ecologicamente viável têm sido intensificados, com o controle biológico baseado na utilização de biopesticidas, sendo altamente incentivado, por ser uma alternativa promissora aos defensivos químicos (SANTOS, 2011).

Um dos mais difundidos inseticidas biológicos, de natureza microbiana, é o Bacillus thuringiensis. Esta bactéria Gram positiva, isolada do solo, tem capacidade de produzir endotoxinas que afetam severamente o sistema digestivo das lagartas, levando-as a morte (HORTA et al., 2017). Foi relatado que bactérias do gênero Bacillus e Pseudomonas isoladas de solos contaminados por hidrocarbonetos do petróleo, com capacidade de produzir metabólitos bioativos, denominados biossurfactantes, também apresentaram ação inseticida, larvicida e repelente contra mosquitos (GEETHA et al., 2012; SILVA et al., 2015).

Devido à crescente demanda por produtos alternativos para o controle das pragas que causam grandes prejuízos econômicos à cultura do milho, o presente trabalho teve como objetivo avaliar a capacidade da linhagem bacteriana 358.1 isolada do petróleo e do sobrenadante da cultura livre de células, no controle de lagartas de $3^{\circ}$ instar de $S$. frugiperda, comparando as taxas de mortalidade e efeitos sobre seu desenvolvimento à intoxicação por inseticidas químicos comerciais

\section{MATERIAL E MÉTODOS}

No Laboratório de Seletividade de Produtos Químicos (LSPQ) da Universidade Federal Rural do Semiárido (UFERSA), foi realizada uma criação massal de $S$. frugiperda. Lagartas e adultos dessa espécie foram coletados em campos de produção da cultivar de milho AG 1051, nos municípios de Limoeiro do Norte, Ceará e Upanema, Rio Grande do Norte. Os exemplares foram transferidos para LSPQ, identificados com etiquetas contendo data e nome do coletor, e acondicionados em recipientes de vidro vedados. As lagartas foram mantidas em tubos de ensaio com $8 \mathrm{~cm}$ de comprimento por $2 \mathrm{~cm}$ de diâmetro e alimentadas ad libitum diariamente com folhas da mesma cultivar, AG 1051. Os adultos foram mantidos em gaiolas de cloreto de polivinila (PVC) de $20 \mathrm{~cm}$ de altura e $10 \mathrm{~cm}$ de diâmetro, alimentados com solução de mel a 10\% (Adaptado de GIOLO et al. 2002). Nas gaiolas, acondicionaram-se 3 a 4 casais, as posturas foram coletadas diariamente e depositadas em béqueres de vidro com capacidade de $500 \mathrm{~mL}$. Após eclosão dos ovos as lagartas de $1^{\circ}$ instares foram individualizadas em tubos de ensaio nas mesmas dimensões citadas anteriormente, com sua extremidade vedada com filme de PVC laminado e alimentadas diariamente ad libitum com folhas de milho, mantendo um número de exemplares suficientes para os testes e manutenção da criação massal.

Paralelamente foi realizado cultivo bacteriano da linhagem 358.1 proveniente da coleção de microrganismos do Laboratório de Microbiologia Ambiental da UFERSA. O inóculo bacteriano utilizado nos experimentos apresentou concentração celular de $10^{8} \mathrm{UFC} / \mathrm{mL}$ padronizado pela técnica da microgota (Adaptada de Andrade et al., 1994). Para realização dos testes de contato das células bacterianas com os insetos, a cultura bacteriana foi preparada a partir do cultivo de uma colônia de $358.1 \mathrm{em} 5 \mathrm{~mL}$ de caldo nutritivo por $24 \mathrm{~h}$ a $37^{\circ} \mathrm{C}$, sob agitação contínua de $150 \mathrm{rpm}$. No segundo teste, envolvendo a ação de metabólitos bioativos, as células foram cultivadas em Meio Mineral contendo micronutrientes, por $48 \mathrm{~h}$ a $30^{\circ} \mathrm{C}$, também sob agitação. (Adaptado de MORÁN et al., 2000). Posteriormente, o meio foi centrifugado a $9.000 \mathrm{~g}$ por $10 \mathrm{~min}$ para separação do sobrenadante da cultura. O sobrenadante livre de células foi utilizado em testes de atividade tensoativa, baseando-se em Youssef et al. (2004), para verificar a produção de biossurfactante.

Obtida a linhagem bacteriana 358.1 e seu sobrenadante, os testes de toxicidade em lagartas de $3^{\circ}$ instares em arenas foliares foram realizados com seis tratamentos: controle negativo (solução salina a $0,9 \%$ ); controle positivo (45 g i.a./ ha de fenpropatrina - inseticida sintético); sobrenadante da cultura livre de células; cultura da linhagem 358.1 pura em meio líquido; cultura diluída a $75 \%$ e cultura diluída a $50 \%$. Foram utilizadas 96 lagartas no bioensaio, 16 lagartas por tratamento, sendo duas lagartas por repetição, totalizando 8 repetições em cada tratamento.

Para aplicação dos tratamentos, arenas foliares de milho com dimensões de 4,0 × 4,0 cm, foram depositadas uma a uma em placas de Petri de $10 \mathrm{~cm}$ de diâmetro. Em seguida os tratamentos foram cuidadosamente aplicados no volume de $24 \mu \mathrm{L}$ por folha.

Após uma hora da aplicação dos produtos analisados e absorção pelas áreas foliares, lagartas de $S$. frugiperda no $3^{\circ}$ instares foram transferidas sobre as arenas, uma lagarta por 
placa, evitando o canibalismo. Foram avaliados os seguintes parâmetros biológicos: taxa de mortalidade após $1 \mathrm{~h}, 6 \mathrm{~h}, 12 \mathrm{~h}$ e $24 \mathrm{~h}$ de pulverizações dos tratamentos, e em seguida, uma vez ao dia em intervalos de 24 horas, até a morte da lagarta, pupação e/ou emergência do adulto. Efeitos no desenvolvimento das lagartas sobreviventes também foram observados, como inviabilidade pupal e má formação morfológica de adultos.

Os dados obtidos foram submetidos ao teste de normalidade de Shapiro-Wilk com o nível de significância de $5 \% \quad(\mathrm{P}<0,05)$. Considerando que os dados tendiam a normalidade (paramétricos), aplicou-se Análise de Variância (ANOVA) e as médias comparadas pelo teste de Tukey, ambas com o nível de significância de $5 \%(\mathrm{P}<0,05)$, para verificar as diferenças significativas entre os grupos testados. Para todos os parâmetros analisados foi utilizado o software estatístico SAS (SAS, 1995), com exceção à mortalidade acumulada no tempo para lagartas de $3^{\circ}$ instar em áreas foliares não esterilizadas, na qual foi utilizado o software estatístico SISVAR (FERREIRA, 1998).

\section{RESULTADOS E DISCUSSÃO}

A mortalidade acumulada de lagartas de $3^{\circ}$ instar de $S$. frugiperda (Figura 1) relatou que o único tratamento que diferiu estatisticamente dos demais foi o inseticida fenpropatrina, e somente $48 \mathrm{~h}$ após a aplicação dos tratamentos. Os demais produtos não apresentaram diferença estatística nos tempos avaliados. Copping e Menn (2000) avaliaram cepas de $B$. thuringiensis isoladas de solo no controle de lagartas de $1^{\circ}$ instar de $S$. frugiperda e com $120 \mathrm{~h}$ após aplicação dos tratamentos. Das 385 cepas testadas apenas cinco promoveram mortalidade dos insetos, que variaram de 77 a $100 \%$. Estes resultados diferem dos obtidos no presente ensaio, porém é importante salientar que os autores citados, utilizaram lagartas de $1^{\circ}$ instar, as quais tendem ser mais suscetíveis à ação de patógenos quando comparadas às lagartas de $3^{\circ}$ instar (LIMA et al., 2010).

Em relação à taxa de mortalidade, $50 \%$ foi obtido pelo inseticida fenpropatrina, o maior índice, seguido de 12,5\% para cultura total de células e cultura de células diluídas a
$50 \%$, com o sobrenadante da cultura e cultura de células diluídas a $75 \%$ com $0 \%$ de mortalidade (Tabela 1). Lima et al. (2009), ao trabalharem com formulados comerciais de nim e B. thuringiensis subsp. Aizawai - Bta, visando o controle de $S$. frugiperda, obtiveram resultados bastante promissores para implantação destes em um sistema de controle de pragas, chegando a $100 \%$ de mortalidade das lagartas nos ensaios.

Batista et al. (2005) realizaram um estudo de prospecção de cepas de $B$. thuringiensis tóxicas a $S$. frugiperda, das 1375 linhagens testadas apenas 26 causaram $100 \%$ de mortalidade, e destas apenas três passaram nos testes de dose, ou seja, mantinham a eficiência de mortalidade em baixas concentrações, sendo selecionadas como promissoras para produção de bioinseticidas no controle de $S$. frugiperda. Linhagens bacterianas ou suas formulações comerciais com capacidade de controlar $S$. frugiperda, com grande eficiência na mortalidade de insetos, requerem um estudo intenso. Os primeiros relatos realizados com Bt visando análises de testes de eficiência sobre artrópodes pragas não foram promissores. Waquil et al. (1982) obtiveram resultados semelhantes ao do presente trabalho quando comparam inseticidas químicos ao $\mathrm{Bt}$, tendo os inseticidas químicos apresentado capacidade de causar mortalidade e de controlar a população de $S$. frugiperda, enquanto o inseticida biológico (Bt) não teve ação inseticida.

A utilização de Bt no controle de $S$. frugiperda é uma tecnologia já bem difundida, tanto na forma de produção de milho transgênico como na utilização de inseticidas formulados a base dessa bactéria. No entanto, pesquisas já indicam que algumas populações de $S$. frugiperda já apresentam resistência a essa bactéria, possivelmente uma seleção natural pelo uso equivocado desses inseticidas biológicos (JAKKA et al., 2014). Estudos em Porto Rico relataram a presença de populações de $S$. frugiperda resistentes à proteína Cry1F expressa no milho Bt (STORER et al., 2010). Em 2014, no Brasil, observou-se também a evolução da resistência de $S$. frugiperda à proteína Cry1F (FARIAS et al., 2014). Tais relatos reforçam a necessidade de contínua pesquisa e procura de linhagens bacterianas que tenham a capacidade de controlar esta praga, evitando aumento exponencial de populações resistentes.

Figura 1. Curva de mortalidade acumulada de lagartas do $3^{\circ}$ ao $6^{\circ}$ instar ao longo do tempo. Letras minúsculas distintas representam diferenças estatísticas pelo teste de Tukey ao nível de significância de 0,05. Fenpropatrina (+) e solução salina (-).

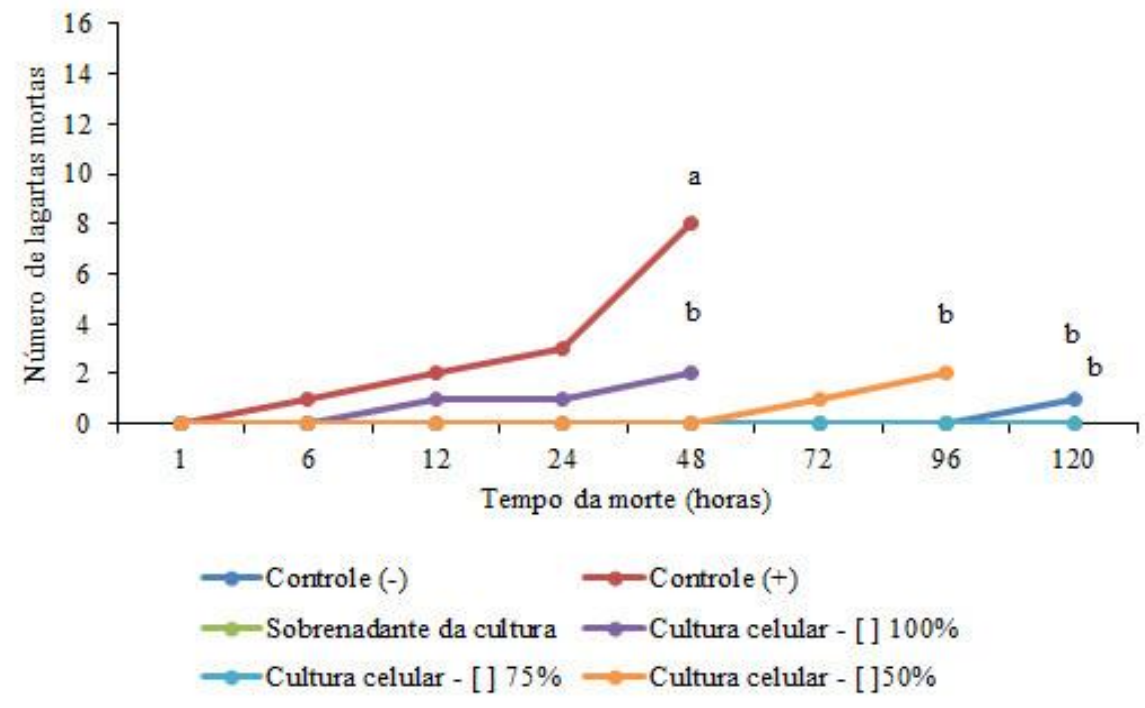


Como citado anteriormente houve baixa mortalidade de lagartas de $S$. frugiperda ocasionada pela cultura de células da linhagem 358.1 e do sobrenadante da cultura livre de células. Uma hipótese para essa baixa eficiência de controle pode estar associada à capacidade destas lagartas diferenciarem os locais contaminados e não contaminados pela bactéria nas arenas foliares, diminuindo a taxa efetiva dos $16 \mathrm{~cm}^{2}$ de áreas foliares tratadas em causar efeito sobre a sobrevivência das lagartas, relatos da capacidade dessa detecção dos insetos foram constatados por Schmutterer (1990).

Lima et al. (2010) ao avaliarem a bioatividade de formulados de nim e Bt sobre lagartas de $S$. frugiperda, com variação na forma de aplicação de seus tratamentos, imersão ou pulverização foliar, obtiveram resultados bastante expressivos, com os formulados de nim e de Bt. Vale salientar que no bioensaio proposto por Lima et al. (2010), em ambas as técnicas de contaminação das folhas, imersão ou pulverização prévia antes de ofertá-las às lagartas, promoveram um aumento do volume de calda por área foliar, garantindo boa cobertura da área pelos tratamentos analisados e consequentemente promovendo maior ingestão pelas lagartas dos produtos analisados. Apesar da imersão sugerir uma maior abrangência da área foliar pelos tratamentos utilizados e consequentemente maior ingestão do produto pelas lagartas, as maiores taxas de mortalidade relatadas pela imersão foram de $82,9 \%$ para o formulado de nim e de $75 \%$ para o formulado de $\mathrm{Bt}$, sendo menores que as taxas de mortalidades observadas quando esses tratamentos foram pulverizados, que foi de $100 \%$ em ambos tratamentos. Tais resultados sugerem que a forma de aplicação de bioinseticidas no controle de insetos pragas, como lagartas do cartucho, está intimamente ligada a uma maior eficiência da ação inseticida dos compostos utilizados.

De acordo com a Tabela 1, a taxa de mortalidade na fase de pupa foi maior nos tratamentos com cultura celular, variando de 43,75 a $62,5 \%$ e no sobrenadante da cultura com $62,5 \%$, enquanto que o controle positivo (fenpropatrina) e negativo (solução salina) foram de $25 \%$ e 31, 25\%, respectivamente. Os resultados obtidos para os tratamentos biológicos (cultura celular e sobrenadante da cultura livre de células) podem ser atribuídos aos efeitos nocivos na fisiologia da fase jovem desse inseto, ou seja, alteração no processo de muda ou metamorfose, ocasionando a morte na fase pupal, dados que se assemelham aos obtidos por Viana e Prates (2003).

Tabela 1. Mortalidade (\%) e duração (média \pm erro padrão) de lagartas e pupas, quando lagartas de $3^{\circ}$ instar de $S$. frugiperda foram alimentadas com arenas foliares, de acordo com cada tratamento experimental.

\begin{tabular}{|c|c|c|c|c|c|c|}
\hline \multirow{2}{*}{ Tratamentos } & \multirow{2}{*}{$\begin{array}{l}\text { População } \\
\text { inicial dos } \\
\text { tratamentos }\end{array}$} & \multicolumn{2}{|c|}{ Lagarta de $3^{\circ}-6^{\circ}$ instar } & \multicolumn{3}{|c|}{ Pupa } \\
\hline & & Mortalidade & Duração (Dias) & $\mathrm{N}^{\mathrm{o}}$ de puparios & Mortalidade & Duração (Dias) \\
\hline $\begin{array}{c}\text { Controle positivo } \\
\text { (Fenpropatrina) }\end{array}$ & 16 & $8(50 \%)$ & $14 \pm 0,65 \mathrm{a}$ & $8(50 \%)$ & $4(25 \%)$ & $8,3 \pm 0,53 \mathrm{a}$ \\
\hline $\begin{array}{l}\text { Controle Negativo } \\
\text { (Solução salina) }\end{array}$ & 16 & $1(6,25 \%)$ & $10,7 \pm 0,63 \mathrm{~b}$ & $13(81,25 \%)$ & $5(31,25 \%)$ & $6,8 \pm 0,75 a$ \\
\hline $\begin{array}{l}\text { Sobrenadante livre de } \\
\text { células }\end{array}$ & 16 & $0(0 \%)$ & $12,2 \pm 0,65 a b$ & $16(100 \%)$ & $10(62,5 \%)$ & $7,7 \pm 0,33 \mathrm{a}$ \\
\hline Cultura total de células & 16 & $2(12,5 \%)$ & $13,4 \pm 0,87 \mathrm{ab}$ & $14(87,5 \%)$ & $9(56,25 \%)$ & $8 \pm 0,58 \mathrm{a}$ \\
\hline $\begin{array}{l}\text { Cultura de células } \\
\text { diluídas a } 75 \%\end{array}$ & 16 & $0(0 \%)$ & $12,4 \pm 0,66 a b$ & $14(87,5 \%)$ & $10(62,5 \%)$ & $7 \pm 0,41 \mathrm{a}$ \\
\hline $\begin{array}{l}\text { Cultura de células } \\
\text { diluídas a } 50 \%\end{array}$ & 16 & $2(12,5 \%)$ & $13,2 \pm 0,71 \mathrm{ab}$ & $11(68,75 \%)$ & $7(43,75)$ & $8 \pm 0,41 \mathrm{a}$ \\
\hline
\end{tabular}

${ }^{1}$ Os valores seguidos pela mesma letra nas colunas não diferem estatisticamente pelo teste Tukey no nível de significância de 0,05 .

A razão sexual observada foi significativa considerando a proporção de 1:1 (fêmeas/ machos) para o controle positivo, negativo e cultura de células da linhagem 358.1 (diluída a $75 \%$ ), para uma razão maior de fêmeas e do tratamento cultura de células da linhagem 358.1 (diluída a 50\%), para uma razão maior no número de machos (Tabela 2). As diferenças das razões sexuais observadas podem ser provenientes da alimentação das lagartas das áreas contaminadas com os resíduos dos produtos analisados nas folhas. Constanski et al. (2016) observaram em seus estudos maior porcentagem de machos de $S$. frugiperda quando alimentadas com óleo de nim associado ao pós-inerte caulim, em folhas de tomateiro. Por outro lado, Waquil et al. (2016) ao alimentarem lagartas de $S$. frugiperda com milhos Bt não obtiveram diferenças na razão sexual de suas populações. Variações e/ou aplicações de substâncias na dieta dessas lagartas podem alterar a razão sexual da população. Estudos alertaram, que a mortalidade nem sempre é alcançada, porém, efeitos subsequentes à fase exposta ao tratamento podem expressar danos subletais, tanto fisiológicos como morfofisiológicos. Storch et al. (2014), ao avaliar a ação tópica de dois inseticidas, malationa e lambdacialotrina, não conseguiu induzir mortalidade em lagartas de $S$. frugiperda, porém promoveu um efeito secundário quando estas eram expostas aos inseticidas na fase larval, levando a uma redução do percentual de ovos viáveis.

Dentre os efeitos deletérios e subletais observados entre os tratamentos analisados para o controle de S. frugiperda, a não emergência e a deformação morfológica das asas de alguns adultos mereceram atenção. Nos tratamentos com cultura celular da linhagem 358.1 em sua concentração total e cultura celular diluída a $75 \%, 6,25 \%$ dos adultos não conseguiram emergir completamente, ficando com parte do corpo preso à pupa. Nos tratamentos com sobrenadante da cultura livre de células e cultura celular diluída (50\%), 12,5\% e $18,75 \%$ dos adultos, respectivamente, apresentaram deformidades morfológicas nas asas (Figura 2). Esses resultados são semelhantes aos de Martinez et al. (2001) quando analisaram lagartas de $3^{\circ}$ instar de $S$. littoralis (Boisduval, 1833) (Lepidoptera: Noctuidae), porém, alimentas com dieta artificial associadas a doses de azadiractina, um composto regulador de crescimento que interfere no sistema neuroendócrino dos insetos. 
Deformidades morfológicas atribuídas às substâncias ou metabólitos podem causar efeitos adversos nos hormônios do crescimento, como na ecdisona e hormônio juvenil (GARCIA et al., 2012). Loeck et al. (2007) avaliaram inseticidas que podiam ser usados para alterar a metamorfose e promover deformidades morfológicas, atuando como um agonista aos ecdisteroides. Mais recentemente, deformidades na fase adulta foram registradas por Modolon et al. (2016), quando aplicaram sais de sílica (Silicea terra) e um preparado homeopático na dieta de $S$. frugiperda.

Tabela 2. Razão sexual e efeito subletal sobre adultos faratos, quando lagartas de $3^{\circ}$ instar de $S$. frugiperda foram alimentadas com arenas foliares contaminadas, de acordo com cada tratamento experimental.

\begin{tabular}{|c|c|c|c|c|c|c|}
\hline \multirow[b]{2}{*}{ Tratamentos } & \multirow[b]{2}{*}{$\begin{array}{l}\text { População } \\
\text { inicial dos } \\
\text { tratamentos }\end{array}$} & \multicolumn{3}{|c|}{ Emergência } & \multicolumn{2}{|c|}{ Adulto Farato } \\
\hline & & $\mathrm{N}^{\circ}$ Macho & No Fêmea & Razão sexual & $\begin{array}{c}\text { Emergiu com } \\
\text { asas } \\
\text { atrofiadas }\end{array}$ & $\begin{array}{l}\text { Não emergiu } \\
\text { completamente }\end{array}$ \\
\hline $\begin{array}{l}\text { Controle positivo } \\
\text { (Fenpropatrina) }\end{array}$ & 16 & $1(6,25 \%)$ & $3(18,75 \%)$ & 0,75 & $0(0 \%)$ & $0(0 \%)$ \\
\hline $\begin{array}{l}\text { Controle Negativo } \\
\text { (Solução salina) }\end{array}$ & 16 & $2(12,5 \%)$ & $6(37,5 \%)$ & 0,75 & $0(0 \%)$ & $0(0 \%)$ \\
\hline $\begin{array}{l}\text { Sobrenadante livre de } \\
\text { células }\end{array}$ & 16 & $2(12,5 \%)$ & $4(25 \%)$ & 0,67 & $2(12,5 \%)$ & $0(0 \%)$ \\
\hline Cultura total de células & 16 & $2(12,5 \%)$ & $2(12,5 \%)$ & 0,5 & $0(0 \%)$ & $1(6,25 \%)$ \\
\hline $\begin{array}{l}\text { Cultura de células } \\
\text { diluída a } 75 \%\end{array}$ & 16 & $1(6,25 \%)$ & $3(18,75 \%)$ & 0,75 & $0(0 \%)$ & $1(6,25 \%)$ \\
\hline Cultura diluídas a $50 \%$ & 16 & $3(18,75 \%)$ & $1(6,25 \%)$ & 0,25 & $3(18,75 \%)$ & $0(0 \%)$ \\
\hline
\end{tabular}
0,05 .

Produtos biológico com capacidade de controlar insetos vêm sendo cada vez mais pesquisados. Bactérias, fungos, vírus e extratos de plantas são os mais promissores (BARBOSA et al., 2011). Porém poucos trabalhos sobre a avaliação do efeito inseticida de metabólitos produzidos por bactérias, como os biossurfactantes, foram descritos para o controle de lepidópteras. Por outro lado, a atividade inseticida já foi caracterizada, o que pode explicar as maiores taxas de mortalidade ocasionadas no estágio de pupa de $S$. frugiperda (Tabela 1). Esses dados reforçam a importância de estudos mais aprofundados sobre os efeitos dos metabólitos produzidos por bactérias sobre artrópodes pragas (GEETHA et al.,2012; PARREIRA et al., 2013; SILVA et al.,2015). Como por exemplo, os estudos realizados por Khedher et al. (2017), que demonstraram a capacidade inseticida do biossurfactante produzido por $B$. amyloliquefaciens no controle de populações de $S$. littoralis.

Figura 2. Danos morfológicos nas asas de adultos recém emergidos de $S$. frugiperda quando lagartas de $3^{\circ}$ instar foram contaminadas ao sobrenadante da cultura livre de células (A) ou cultura de células diluídas a $50 \%$ (B).

A
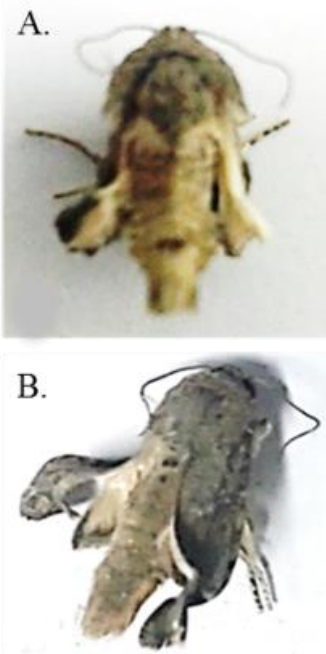

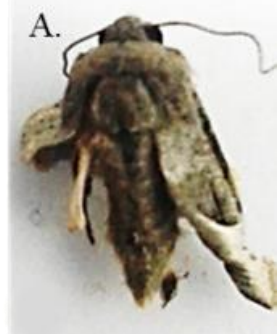

B.

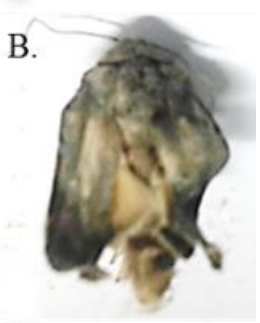

\section{CONCLUSÕES}

A linhagem bacteriana 358.1 mostrou ação na fisiologia de Spodoptera frugiperda Smith, prolongando o tempo larval e interferindo na sua fisiologia no momento da sua metamorfose (fase de pupa) e na emergência dos adultos, com presença de asas atrofiadas. O único momento em que o controle positivo (fenpropatrina) foi diferente estatisticamente dos outros tratamentos testados foi 48 horas após disponibilização de áreas foliares contaminadas às lagartas.

\section{REFERÊNCIAS}

ANDRADE, D. S.; HAMAKAWA, P. J. Estimativa do número de células viáveis de rizóbio no solo e em inoculantes por infecção em plantas. In: Hungria, M.; Araujo, R. S. (ed.) Manual de métodos empregados em estudos de microbiologia agrícola. Brasília: EMBRAPA-SPI, 1994. p. 63-94.

BARBOSA, R. H.; KASSAB, S. O.; FONSECA, P. R. B.; ROSSONI, C.; SILVA, A. S. Inseticidas biológico e natural no controle da Spodoptera frugiperda (J. E. SMITH, 1797) (Lepidoptera: Noctuidae) em milho cultivado em condições de campo. Revista Verde de Agroecologia e Desenvolvimento Sustentável, v. 6, n. 3, p. 247-251, 2011.

BATISTA, A.; MELATTI, V.; DEMO, C.; MARTINS, E.; PRAÇA, L.; GOMES, A. C. M. M.; FALCÃO, R.; BROD, C.; MONNERAT, R. G. Prospecção de estirpes de Bacillus thuringiensis tóxicas a Spodoptera frugiperda (Screening of Bacillus thuringiensis strains toxic to Spodoptera frugiperda. Embrapa Recursos Genéticos e Biotecnologia, v. 81, n. p. 119, 2005.

CONSTANSKI, K. C.; ZORZETTI, J.; SANTORO, P. H.; HOSHINO, A. T.; NEVES, P. M. O. J. Inert powders alone or in combination with neem oil for controlling Spodoptera eridania and Spodoptera frugiperda (Lepidoptera: Noctuidae) 
larvae. Semina: Ciências Agrárias, v. 37, n. 4, p. 1801-1810, 2016. http://dx.doi.org/10.5433/1679-0359.2016v37n4p1801

CONAB. COMPANHIA NACIONAL de ABASTECIMENTO. Acompanhamento da safra brasileira: GRÃOS.2014 <http://www.conab.gov.br/> Acesso em: 05 Nov. 2016.

COPPING, L. G.; MENN, J. J. Biopesticides: a review of their action, applications and efficacy. Pest Management Science, v. 56, n. 8, p. 651 - 676, 2000. http://dx.doi.org/10.1002/1526-4998(200008)56:8<651::AIDPS201>3.0.CO;2-U.

EMBRAPA. EMPRESA BRASILEIRA DE PESQUISA AGROPECUÁRIA. Países africanos pedem ajuda ao Brasil para controlar lagarta-do-cartucho. (2018) <https://www.embrapa.br/busca-de-noticias/-

/noticia/32540599/paises-africanos-pedem-ajuda-ao-brasilpara-controlar-lagarta-do-cartucho> Acesso em: 26 Jun. 2018.

FARIAS, J. R.; ANDOW, D. A.; HORIKOSHI, R. J.; SORGATTO, R. J.; FRESIA, P.; SANTOS, A. C.; OMOTO, C. Field-evolved resistance to Cry1F maize by Spodoptera frugiperda (Lepidoptera: Noctuidae) in Brazil. Crop Protection, v. 64, n. 2, p. 150-158, 2014. http://dx.doi.org/10.1016/j.cropro.2014.06.019

FERREIRA, D. F. Sisvar - sistema de análise de variância para dados balanceados. Lavras: UFLA, p. 19, 1998.

GARCIA, E. S.; CASTRO, D. P.; FIGUEIREDO, M. B.; GONZALES, M. S.; AZAMBUJA, P. O Sistema Neuroendócrino de Insetos. In: NETO, M. A. C. S.; WINTER, C.; TERMIGNONI, C. (ed.) Tópicos Avançados em Entomologia Molecular. Rio de Janeiro: Instituto Nacional de Ciência e Tecnologia em Entomologia Molecular, 2012. p. 207-232.

GEETHA, I.; KUMMANKOTTIL, P.P.; MANONMANI, A.M. Mosquito adulticidal activity of a biosurfactant produced by Bacillus subtilis subsp subtilis. Pest Management Science, v. 68, n. 1, p. 1447-1450, 2012. http://dx.doi.org/10.1002/ps.3324

GIOLO, F.; GRUTZMACHER, A.; GARCIA, M.; BUSATO, G. Parâmetros biológicos de Spodoptera frugiperda (J. E. Smith, 1797) (Lepidoptera: Noctuidae) oriundas de diferentes localidades e hospedeiros. Revista Brasileira de Agrociência, $\begin{array}{llllll}\text { v. } \quad 8, \quad \text { n. } & 3, & \text { p. } 219-224, & 2002 .\end{array}$ http://dx.doi.org/10.18539/CAST.V8I3.472

HORTA, A. B.; PANNUTI, L. E. R.; BALDIN, E. L. L.; FURTADO, E.L. Toxinas inseticidas de Bacillus thuringiensis. In: RESENDE, F. V.; SOCCOL, L. E. R.; FRANÇA, L. R. (eds.). Biotecnologia Aplicada à Agro\&Indústria. 1. ed. São Paulo: Editora Blucher, 2017. cap. 21, p. 737-774. http://dx.doi.org/10.5151/9788521211150-21

JAKKA, S. R. K.; KNIGHT, V. R.; JURAT-FUENTES, J. L. Spodoptera frugiperda (J. E. Smith) with field-evolved resistance to $\mathrm{Bt}$ maize are susceptible to Bt pesticides. Journal of Invertebrate Pathology, v. 122, p. 52-54, 2014. https://doi.org/10.1016/j.jip.2014.08.009.

KHEDHER, S. B.; BOUKEN, H.; DAMMAK, M.; FEKI, O. K.; ODAWARA, T. S.; MESRATI, L. A.; TOUNSI, S. Combinatorial effect of Bacillus amyloliquefaciens AG1 biosurfactant and Bacillus thuringiensis Vip3Aa16 toxin on Spodoptera littoralis larvae. Journal of Invertebrate Pathology, v. 144, p. 11-17, 2017. http://dx.doi.org/10.1016/j.jip.2017.01.006.

LIMA, M. P. L.; DE OLIVEIRA, J. V.; MARQUES, E. J. Manejo da lagarta-do-cartucho em milho com formulações de nim e Bacillus thuringiensis subsp. aizawai. Ciência Rural, v. 39, n. 4, p. 1215-1218, 2009. http://dx.doi.org/10.1590/S0103-84782009005000066.

LIMA, M. P. L.; OLIVEIRA, J. M. G. C.; MARQUES, E. J.; CORREIA, A. A. Bioactivity of neem (Azadirachta indica A. Juss, 1797) and Bacillus thuringiensis subsp. aizawai formulations in larvae of Spodoptera frugiperda (J. E. Smith) (Lepidoptera: Noctuidae). Ciência e Agrotecnologia, v. 34, n. 6, p. 1381-1389, 2010. http://dx.doi.org/10.1590/S141370542010000600004 .

LOECK, A. E.; STORCH, G.; BORBA, R. da S.; MAGANO, D. A.; MORAES, C. L.; GRÜTZMACHER, A. D. Efeito de inseticidas aplicados em doses subletais sobre a dieta artificial e em lagartas de Anticarsia gemmatalis (Lepidoptera: Noctuidae). Revista Brasileira de Agrociência, v. 13, n. 2, p. 175-179,

http://dx.doi.org/10.18539/CAST.V13I2.1358.

2007.

MARTINEZ, S. S., HELMUT, F., EMDEN, V. Growth disruption, abnormalities and mortality of Spodoptera littoralis (Boisduval) (Lepidoptera: Noctuidae) caused by Azadirachtin. Neotropical Entomology, v.30, n. 1 p.113-125, 2001. http://dx.doi.org/10.1590/S1519-566X2001000100017.

MODOLON, T. A.; ALVES, L. F. A.; PIETROWSKI, V.; GUIMARÃES, A. T. B.; MARCIO, J. F. Parâmetros biológicos de Spodoptera frugiperda (J. E. SMITH, 1797) (Lepidoptera: Noctuidae) em milho tratado com preparados homeopáticos. Cadernos de Agroecologia, v. 10, n. 3, p. 1-5, 2016.

MORÁN, A. C.; OLIVEIRA, N.; COMMENDATORE, M.; ESTEVES, J. L.; SIÑERIZ F. Enhancement of hydrocarbon waste biodegradation by addition of a biosurfactant from Bacillus subtilis O9. Biodegradation, v. 11, n.1, p. 65-71, 2000. http://dx.doi.org/10.1023/A:1026513312169.

PARREIRA, A. G.; RACHID, M. B.; MANSO, D. T. G.; ALVES, S. N.; CASTRO, A. A. P. O.; SANTOS, G.; ASSIS, G.; SILVA, B. A. B.; TOLOTA, M. R. Avaliação do efeito de surfactantes biológicos e sintéticos sobre larvas, pupas e insetos adultos de Culex sp. e Aedes aegypti. $27^{\circ}$ Congresso Brasileiro de Microbiologia. Natal - RN, set, 2013. Disponível em: <http://www.sbmicrobiologia.org.br/cd27cbm/resumos/R126 5-1.html>. Acesso em: 29 out. 2014. 
SANTOS, T. T.; VARAVALlO, M. A. Aplicação de microrganismos endofíticos na agricultura e na produção de substâncias de interesse econômico. Semina: Ciências Biológicas e da Saúde, v. 32, n. 2, p. 199-212, 2011. http://dx.doi.org/10.5433/1679-0367.2011v32n2p199.

SAS - Statistical Analysis System. SAS user's guide for windowns environment. $6.11 \mathrm{ed}$. Cary : SAS Institute, 1995.

SCHMUTTERER, H. Properties and potential of natural pesticides from the neem tree, Azadirachta indica. Annual Review of Entomology, v. 35, p. 271-297, 1990. http://dx.doi.org/10.1146/annurev.en.35.010190.001415.

SILVA, V. L.; LOVAGLIO, R .B.; VON ZUBEN, C. J.; CONTIERO, J. Rhamnolipids: solution against Aedes aegypti? Frontiers in Microbiology, v.6, p. 1-5, 2015. https://doi.org/10.3389/fmicb.2015.00088.

SOBER. SOCIEDADE BRASILEIRA de ECONOMIA, ADMINISTRAÇÃO e SOCIOLOGIA RURAL. (2010) <http://www.sober.org.br/> Acesso em: 21 Out. 2014.

STORCH, G.; LOECK, A. E.; REMOR, M.; PELOIA, P. Efeitos subletais de inseticidas sobre Spodoptera frugiperda (J.E. Smith, 1797) (Lepidoptera: Noctuidae), utilizados na cultura do milho. Scientia Agraria Paranaensis, v. 13, n. 1, p. 71-79, 2014. http://dx.doi.org/10.18188/19831471/sap.v13n1p71-79.

STORER, N.P.; BABCOCK, J.M.; SCHLENZ, M.; MEADE, T.; THOMPSON, G.D.; BING, J. W.; HUCKABA, R.M. Discovery and characterization of field resistance to Bt maize: Spodoptera frugiperda (Lepidoptera: Noctuidae) in Puerto Rico. Journal of Economic Entomology, v. 103, n. 4, p. 1031 1038, 2010. https://doi.org/10.1603/EC10040.

USDA. UNITED STATES DEPARTMENT of
AGRICULTURE.

<https://apps.fas.usda.gov/psdonline/app/index.html\#/app/ho me> Acesso em: 05 Nov. 2016.

VIANA, P. A.; PRATES, H. T. Desenvolvimento e mortalidade larval de Spodoptera frugiperda em folhas de milho tratadas com extrato aquoso de folhas de Azadirachto indica. Bragantina, v. 62, n. 1, p. 69-74, 2003. http://dx.doi.org/10.1590/S0006-87052003000100009.

WAQUIL, M. S.; PEREIRA, E. J. G.; CARVALHO, S. S. DE S.; PITTA, R. M.; WAQUIL, J. M.; Mendes, S. M. Índice de adaptação e tempo letal da lagarta-do-cartucho em milho Bt. Pesquisa Agropecuária Brasileira, v. 51, n. 5, p. 563-570, 2016. http://dx.doi.org/10.1590/S0100-204X2016000500017.

WAQUIL, O. M.; VIANA, P. A.; LORDELLO, A. I.; CRUZ, I.; OLIVEIRA, A. C. Controle da lagarta-do-cartucho em milho com inseticidas químicos e biológicos. Pesquisa Agropecuária Brasileira, v. 17, n. 2, p. 163-166, 1982.

WRIGHT, M. G. Biological Control of Invasive Insect Pests. In: ABROL, D. P. (ed.) Integrated Pest Management Current concepts and ecological perspective. San Diego: Elsevier Academic Press, 2014. p. 267-281.
YOUSSEF, N. H.; DUNCAN, K. E.; NAGLE, D. P.; SAVAGE, K. N.; KNAPP, R. M.; MCINERNEY, M. J. Comparison of methods to detect biosurfactant production by diverse microorganisms. Journal of Microbiological Methods,

v. $56, \quad$ p. 2004. http://dx.doi.org/0.1016/j.mimet.2003.11.001. 